\title{
AN OBSERVATION OF COOLING TOWER PLUME EFFECTS ON TOTAL SOLAR RADIATION*
}

\author{
EDWARD RYTAAR \\ Department of Atmospheric and Oceanic Science, University of Michigan,
} Ann Arbor, MI 48104, U.S.A.

(Received 21 April 1977 and in final form 24 June 1977)

\begin{abstract}
Measurements of total solar radiation were made on 7 March 1977. The sky was cloudless but a cooling tower plume occasionally came between the sun and the pyranometer that was used. These measurements resulted in values that were greater than those expected with a cloudless sky. It is likely that reflections from the plume, whose average position was slightly north of an imaginary sun-pyranometer line, were responsible.
\end{abstract}

\section{INTRODUCTION}

As part of a study of the meteorological impact of mechanical-draft cooling towers at the Palisades Nuclear Plant, total solar radiation (direct plus diffuse) on a horizontal surface is measured with pyranometers at stations $0.9 \mathrm{~km}$ east-southeast of the cooling towers and $19 \mathrm{~km}$ east of them. The nuclear plant is located on the southeast shore of Lake Michigan and the pyranometers are at stations 3 and 7 of a 13 station meteorological network (Ryznar et al., 1976). With a west-northwest wind direction, the cooling tower plume passes over the nearer station. If the sun, plume and pyranometer happen to be in alignment, a reduction of total solar radiation as recorded by the pyranometer normally occurs. Smith et al. (1974), for example, shows aerial photographs of the shadowing effect of a plume from a natural draft cooling tower.

The purpose of this communication is to describe a case observed on 7 March 1977 in which the plume occasionally passed between the sun and that pyranometer located $0.9 \mathrm{~km}$ from the cooling towers for most of a cloudless morning, but the average total solar radiation was greater than that expected with a cloudless sky. The timing of the occurrence was such that the author was at the station and was able to verify that (1) except for a short time near 0800 EST when scattered altocumulus clouds passed over the station the sky was completely cloudless except for the cooling tower plume and (2) the pyranometer was level, clean and matched to a calibrated recorder.

\section{PLUME CHARACTERISTICS}

Throughout most of the morning period of recording, characteristics of the plume were noted. In general, as the plume was passing over the station it was becoming fragmented and evaporating rapidly, with complete evaporation taking place about $500 \mathrm{~m}$

* Contribution No. 243 from the Department of Atmospheric and Oceanic Science. farther downwind. It was estimated to be about $200 \mathrm{~m}$ above the ground and $30 \mathrm{~m}$ thick. Because of its small thickness and high transparency, the shadowing of the ground produced by it was hardly discernible. It was not possible, furthermore, to look at the plume in line with the sun long enough to try to match features of the radiation recording with plume behavior. Its average position as it moved east-southeast appeared to be slightly north of an imaginary line connecting sun and pyranometer. It remained nearly over the station until about 1300 EST when the wind shifted gradually to west-southwest, causing its average position to move well north of the station.

\section{CHARACTERISTICS OF THE RECORDING}

The recording of total solar radiation for 7 March 1977 is shown in Fig. 1. It was obtained with a Weather Measure Model 411 pyranometer and a Leeds \& Northrup Speedomax $\mathrm{H}$ recorder. The recording for the time interval between 0830 and 1400 EST shows effects of the plume as it passed either directly between the sun and pyranometer or slightly north or south of an imaginary line connecting them. The solid smooth line drawn through the actual recording is the curve expected for that day if there were no clouds and no plume.

The curve shown is based on two separate assumptions, each of which gave identical values. One assumption was that because the afternoon was cloudless without the plume affecting solar radiation after about 1400 EST, symmetry of the morning and afternoon recordings around solar noon could be assumed. This assumption allowed the cloudless afternoon section of the recording to be matched in time with the corresponding morning section to obtain the curve for a complete cloudless day. The other was that since most of the morning of the following day was also cloudless but uninfluenced by the plume, values of solar radiation could be assumed to be the same as those for the day shown. Additional corroborative information was obtained from total solar 


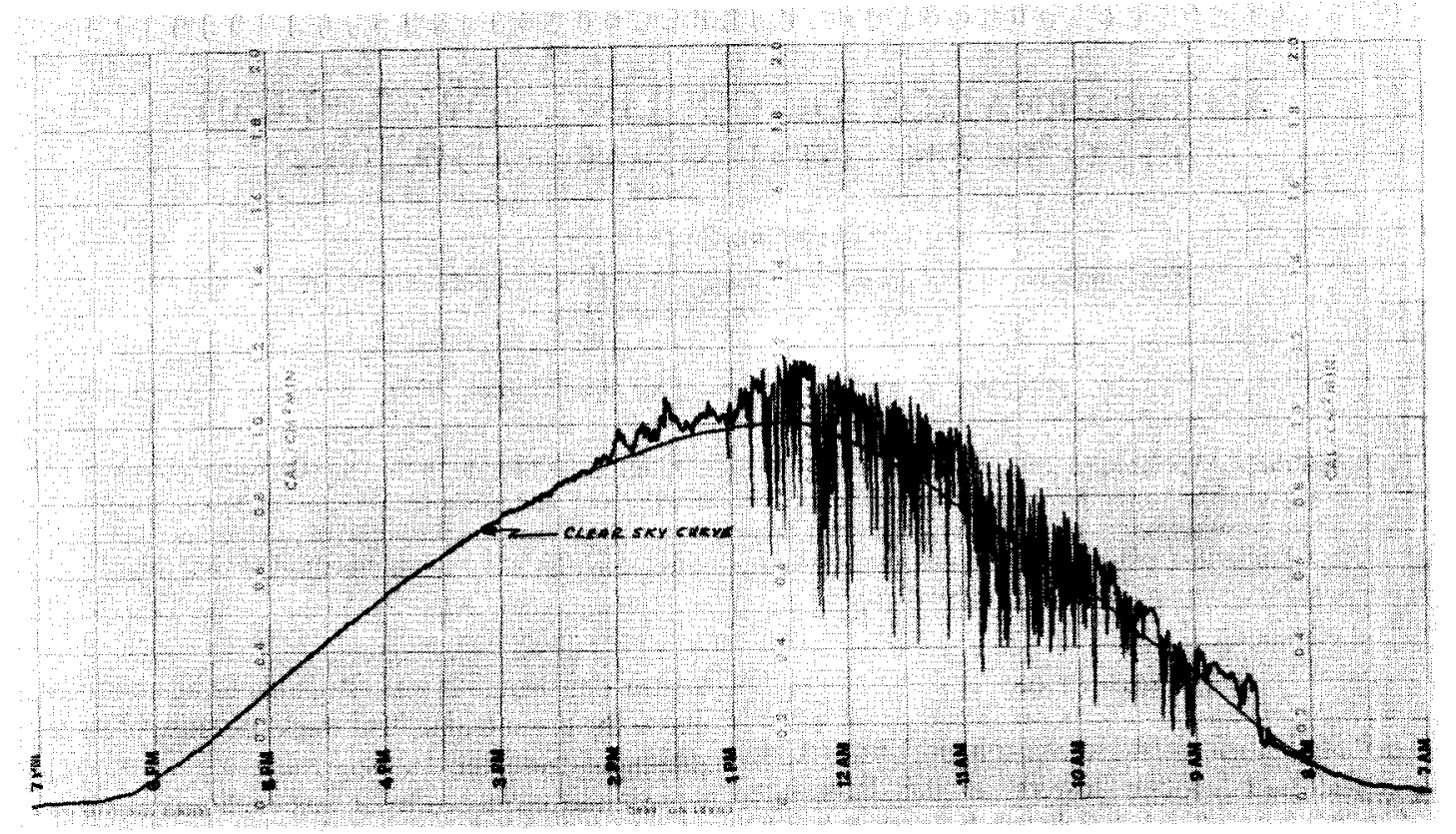

Fig. 1. Recording of total solar radiation on 7 March 1977 for a station $0.9 \mathrm{~km}$ downwind of the Palisades cooling towers. The smooth continuous curve is estimated for a cloudless sky.

radiation recordings made simultaneously at the station $19 \mathrm{~km}$ inland where the sky was also cloudless, there were no plume effects and the same general air mass was present.

A comparison of the two curves shows that the average total solar radiation with the plume is greater than that for a cloudless sky for most of the morning. Occasional values exceeding cloudless values were expected, but a higher average was not. For example, observations reported by others have shown that with certain cloud types and distributions, total solar radiation can briefly exceed cloudless values due to the component reflected from the sides of clouds added to that reccived dircetly through a clear portion of the sky. Observations of this type have been reported by Wesely and Lipschutz (1976) for Argonne, Illinois and by Gates (1965), who measured values which even exceeded the solar constant at elevations of about $3000 \mathrm{~m}$ during scattered cumulus cloud conditions. Kondrat'yev (1965) also cites observations made near Moscow which show total solar radiation with 'sun and clouds' exceeding cloudless values. Because of the random spatial distribution of most natural cumulus clouds, however, shadowing causes average values to become less than cloudless values as the averaging time is increased.

It is likely that the large values observed on 7 March were caused by conditions similar to those produced by natural cumulus clouds. Unlike the random spatial distributions of most clouds of this type, however, the plume held an average position which apparently maintained a large enough component of reflected radiation to produce the observed result. In fact, even though the plume's average position gradually moved northward, it meandered close enough occasionally to cause the longer-lasting increases shown on the recorder trace between 1300 and 1400 EST.

Additional recordings of total solar radiation suspected of having plume and sky conditions similar to those described above are being evaluated. Because such occurrences are infrequent and an observer is at the station only twice each week to service it, there is a lack of not only descriptions of plume behavior over the station but also definitive information on the absence of cloudiness. The importance of such information is evident in the above example, which shows that it is possible for a combination of plume characteristics and positions to cause significant additive effects on solar radiation.

Acknowledgements-The study of cooling tower effects is supported by Consumers Power Company, Jackson, Michigan.

\section{REFERENCES}

Gates D. M. (1965) Radiant energy, its receipt and disposal. In Agricultural Meteorology (Am. met. Soc. met. Monogr.) 6, 1-26.

Kondrat'yev K. Y. (1965) Actinometry. NASA Technical Translation TT F-9712. Washington, D.C.

Ryznar E., Baker D. G. and Moses H. (1976) Coastal meteorological networks to determine effects of nuclear plant cooling systems. Bull. Am. met. Soc. 3, 144I 1446

Smith M. E. et al. (1974) Cooling Towers and the Environment. Amer. Elec. Power Serv. Corp., New York.

Wesely M. L. and Lipschutz R. C. (1976) A method for estimating hourly averages of diffuse and direct solar radiation under a layer of scattered clouds. Solar Energy 18. $467-473$. 